\title{
Dose related acute irritant symptom responses to occupational exposure to sodium borate dusts
}

\author{
Xiaohan Hu, David H Wegman, Ellen A Eisen, Susan R Woskie, Ralph G Smith
}

\begin{abstract}
A repeated measurement design was employed in the study of acute symptoms of eye and respiratory tract irritation resulting from occupational exposure to sodium borate dusts. The symptom assessment of the 79 exposed and 27 unexposed subjects comprised interviews before the shift began and then at regular hourly intervals for the next six hours of the shift, four days in a row. Exposures were monitored concurrently with a personal real time aerosol monitor. Two different exposure profiles, a daily average and short term (15 minute) average, were used in the analysis. Exposure-response relations were evaluated by linking incidence rates for each symptom with categories of exposure. Acute incidence rates for nasal, eye, and throat irritation, and coughing and breathlessness were found to be associated with increased exposure levels of both exposure indices. Steeper exposureresponse slopes were seen when short term exposure concentrations were used. Results from multivariate logistic regression analysis suggest that current smokers tended to be less sensitive to the exposure to airborne sodium borate dust. There was no indication that anhydrous sodium borate was more potent than the other sodium borates in this work environment.
\end{abstract}

Sodium tetraborate is an alkaline salt form of boron. Refined sodium borate usually occurs as colourless

Department of Epidemiology and Biostatistics, University of Massachusetts at Amherst

X Hu

Department of Work Environment, University of Lowell

D H Wegman, E A Eisen, S R Woskie

Environmental Health Science Programme, University of Massachusetts Medical Centre

S R Woskie

School of Public Health, University of Michigan

R G Smith

Occupational Health Programme, Harvard School of Public Health

E A Eisen prismatic crystals, which are refined to produce an anhydrous state $\left(\mathrm{Na}_{2} \mathrm{~B}_{4} \mathrm{O}_{7}\right)$, or with five $\left(\mathrm{Na}_{2} \mathrm{~B}_{4} \mathrm{O}_{7} 5 \mathrm{H}_{2} \mathrm{O}\right)$ or $10\left(\mathrm{Na}_{2} \mathrm{~B}_{4} \mathrm{O}_{7} 10 \mathrm{H}_{2} \mathrm{O}\right)$ moles of hydration. There are an estimated 420000 workers in the United States in various segments of industry who have potential occupational exposure to sodium borate dust. ${ }^{1}$ The Occupational Safety and Health Administration (OSHA), in its recent updating of permissible exposure limits, places sodium borates in the category of sensory irritants. ${ }^{2}$

Whereas the irritant effects of sodium borate dusts on the respiratory tract and mucous membrane of the eye have been recognised and documented, ${ }^{3}$ the quantitative relation between increased irritant symptoms and raised dust concentrations has not been well described. In particular, the aetiological role of short term peak exposures relative to average daily exposure had never been considered. It has been speculated that the exothermic effect of hydration is the underling mechanism of sensory irritation. ${ }^{4}$ Thus it is likely that short term peak exposures would play the major part in evoking irritant symptoms.

This communication reports the results of an investigation that assessed the acute irritant effects of airborn sodium borate dusts on industrial workers. Our study also attempted to examine the relative potency of the different types of sodium borate. The investigation was carried out in a large borax mining and refining plant. The industrial process of mining and refining borax has been described in an earlier study. ${ }^{4}$

\section{Methods}

\section{STUDY POPULATION}

All employees who had direct exposure to refined sodium borate dusts and whose exposures could be adequately characterised according to type of sodium borate were selected. Of those eligible, seventy nine (92\%) participated in the study. A comparison group of 27 subjects in the same plant was also identified, which included all current non-office hourly employees who had no routine exposure to sodium borate dusts (other than background). Most of them were maintenance workers. Exposed and unexposed workers were similar in demographic background 
and history of employment. The health outcome of primary interest was irritation of respiratory or mucous membranes, symptoms that are reversible and, hence could occur many times during a day. As a result the study design allowed for health outcomes and exposure to be directly measured on each subject throughout four, generally consecutive, days. On each of the four study days the subject was surveyed (1) by continuous monitoring for particulate exposure and (2) for health outcomes before the shift began and at hourly intervals for the next six hours.

\section{EXPOSURE ASSESSMENT}

A personal direct reading aerosol monitor (the Miniram: miniature real time aerosol monitor-MIE Inc, Bedford, MA) was used in conjunction with a datalogger system (the Ranger Rustrak, E Greenwich, RI), which allowed continuous measurement of airborne particulate matter throughout the work shift. During actual sampling, the Miniram was used in the active mode, with a flow adapter that enabled pumps calibrated at $2 \mathrm{l} / \mathrm{min}$ to pull the aerosol through the Miniram chamber and on to a filter. At the end of the sample day the filter was placed in a desiccator for 18 hours. The next day a gravimetric determination was made using a Cahn model 29 electrobalance and then the filter was sent to a specialty laboratory for determination of boron content of the dust sample. Because the Miniram aerosol monitor is most sensitive to aerosols in respirable size range and to high humidity, the Miniram was calibrated by a series of side by side area samplers in a separate study so that the real time reading from the data logger could be interpreted as total particulate concentration. An overall $\mathbf{r}^{2}$ for the conversion model based on all dust types combined was 0.93 , indicating that $93 \%$ of the variance in the gravimetric data was explained by the Miniram values.

The recorded continuous Miniram readings were processed by a personal computer to generate different exposure indices. Two separate measures of exposure were selected for use in this analysis: the daily time weighted average (TWA-6) and 15 minute time weighted average (TWA-0.25). For the second, contiguous 15 minute time intervals were defined from the start to the end of each day of observation.

\section{MEASUREMENT OF HEALTH OUTCOMES}

The health outcomes studied included irritant symptoms (eye irritation, nose and throat irritation, nose bleeding, coughing, breathlessness, and sneezing) and peak expiratory flow. To document the occurrence of symptoms, a closed ended questionnaire was developed, designed to be completed within one to two minutes (available upon request to the authors). The survey instrument was pilot tested to confirm that the questions were clear and answerable. Peak expiratory flow was measured by a
mini-Wright peak flow meter with the best of three efforts at each survey selected for study.

A trained field technician was assigned to accompany each subject throughout the day. The technicians administered the hourly questionnaire as well as the peak expiratory flow tests and recorded work activity and any unusual exposure events. They also assisted the industrial hygienists by seeing that the personal monitoring instruments functioned properly. Two to four subjects were tested each day, with the study covering almost an entire year.

At the preshift survey, the questionnaire covered the presence (background) of the seven irritant symptoms, the presence of a common cold, and symptoms of allergy or asthma at the time of the interview. On the subsequent hourly surveys, the questions were slightly altered to cover the development of each of the symptoms during the previous hour. At each survey the subject was also asked about the number of cigarettes smoked in the previous hour, how recently the last one was smoked, and then asked to perform three peak expiratory flow efforts using the same instrument.

After the preshift survey, each time subjects reported one of the symptoms they were asked to indicate the onset time to the closest 15 minute interval within the previous hour and the severity of the symptoms according to a 10 point scale. The 15 minute interval was selected as the best compromise between subject recall and likely time courses of the acute reversible symptoms that were surveyed. Findings on peak expiratory flow and the estimates of severity of symptoms will be the subject of separate reports.

A consequence of this study design was that the two types of health outcomes were surveyed 24 times (just before the start of work on each of the four study days and then hourly for the next six hours). Subjects could report any or all of the seven symptoms at each survey, but each type of symptom could only be reported once per interview. This allowed multiple (up to six) reports of a symptom during a survey day; however, multiple reports of a specific symptom within the same hour were not possible.

As well as the seven individual symptoms, a summary category "any symptom" was created. If a subject reported that eye and nasal irritation occurred within the same hour, these events contributed only a single event to the "any symptom" category. Measuring outcomes repeatedly in the same subjects creates methodological concerns, which we have considered more generally in a separate report. ${ }^{5}$

\section{STATISTICAL ANALYSIS}

Exposure-response

Incident Symptoms-An incident symptom was defined as one that met the following conditions: the same symptom (for example, nasal irritation) was not 
reported in consecutive interviews; or the symptom was reported in consecutive interviews, but with separate and distinct onset times. Also, symptoms reported at the preshift surveys were not treated as incident symptoms. The presence or absence of an incident symptom was determined in each of the six hours of four survey days for each subject. This resulted in up to 24 paired observations of exposure and response for each subject.

At risk Intervals-For analysis of relations between daily average exposure and incidence of symptoms, the denominator for incidence rate was hours at risk. A subject was considered to be at risk of an incident symptom in a given hour unless a symptom that began previously persisted into the hour. Hours at risk were determined separately for each symptom so that a subject might be at risk for cough in a given hour even though he was not at risk for nasal irritation that had persisted from earlier in the day.

For analysis by 15 minute intervals, several other conditions were required. A subject was considered to be at risk in all 15 minute intervals except for those between the interval associated with the onset time of a specific symptom and the next hourly survey. This can be illustrated by considering an hour in which a subject reports nasal irritation to have started in the first 15 minutes of the hour. This subject would no longer be at risk for nasal irritation in the remaining three 15 minute intervals in that hour. He would, however, remain at risk for eye or throat irritation, cough, or breathlessness. As long as the subject continues to report nasal irritation at subsequent hourly surveys the intervening intervals are "not at risk", unless a subsequent onset time is reported. An incident symptom was linked with the 15 minute interval that included the reported time of onset. All other "at risk" 15 minute intervals were linked with the absence of the symptom.

Exposure-response analysis (daily)-All hours (as well as 15 minute intervals) that occurred on a day with a given average daily exposure were assigned that TWA-6. In stratified analysis, categories of exposure were defined based on several current proposals for health based standards. ${ }^{26}$ The incidence rate of each irritant symptom was then estimated within each category and a linear trend test applied using the weighted least squares method in which the weight was the reciprocal of the variance of the incidence rate.

Confounding was handled by modelling incident symptoms as a function of daily average exposure (TWA-6) in a series of logistic regression analyses. A separate logistic model, including age, cigarette smoking, presence of a current cold, and dust type and dust concentration, was fitted to the data for each of the five irritant symptoms, as well as for "any symptom". For these logistic analyses each subject contributed up to four observations to each of the models, one for each person day of observation. A specific symptom was defined as present on a given day if a subject reported at least one incident on that day.

Exposure-response analysis (15 minute exposure)The incidence rate for each symptom was computed as the ratio of the number of symptom episodes to the appropriate period of at risk time. The dose-response relations were evaluated by estimating the incidence rate within categories of increasing exposure levels of TWA- 0.25 and then the linear trends were tested.

As the study design employed repeated measurements of health outcomes potential existed for within subject correlation of successively measured outcomes. To consider this issue, a two stage logistic regression analysis developed by Korn and Whittemore was used. ${ }^{7}$ Only subjects who had a minimum of three symptom reports were included to avoid unstable model parameter estimates. In stage I, a separate logistic model was fitted to the exposure response data for each subject. Three variables were considered in the model: exposure (TWA-0.25), day of the work, and the Markov chain. The Markov chain covariate has two states, 0 or 1 , corresponding to the absence or presence of an incident symptom at the previous 15 minute interval. Odds ratios of any symptom per unit increase in exposure were estimated for each subject. In stage II, the odds ratios were summarised by strata defined by potential confounders and effect modifiers, which included dust type, common cold state, duration of employment, age, and smoking.

\section{DATA COLLECTION}

Collection of information on symptoms was carried out by trained field interviewers under the direction of a field supervisor. Each field interviewer was assigned to two subjects a day and stayed with the same subjects throughout the survey days. As a result of this intensive survey protocol the study of 106 subjects took about one year to complete. As well as supervising the field interviewers, the field supervisor was also responsible for all aspects of exposure

Table 1 Geometric mean and its standard deviation for dust exposure according to dust types and exposure indices

\begin{tabular}{|c|c|c|c|c|c|c|}
\hline \multirow[b]{2}{*}{ Sodium borate } & \multicolumn{3}{|c|}{$T W A-6\left(\mathrm{mg} / \mathrm{m}^{3}\right)$} & \multicolumn{3}{|c|}{$T W A-0.25\left(\mathrm{mg} / \mathrm{m}^{3}\right)$} \\
\hline & No & $G M$ & $G S D$ & No & $G M$ & $G S D$ \\
\hline $\begin{array}{l}\text { Background } \\
\text { All exposed } \\
\text { Anhydrous (AB) } \\
\text { Pentahydrate (P) } \\
\text { Decahydrate (D) } \\
\text { P + D } \\
\text { AB + P + D }\end{array}$ & $\begin{array}{r}105 \\
310 \\
116 \\
53 \\
11 \\
111 \\
19\end{array}$ & $\begin{array}{l}0 \cdot 31 \\
2 \cdot 86 \\
1 \cdot 45 \\
3 \cdot 82 \\
6 \cdot 23 \\
4 \cdot 85 \\
2 \cdot 51\end{array}$ & $\begin{array}{l}2 \cdot 32 \\
3 \cdot 67 \\
3 \cdot 29 \\
3 \cdot 63 \\
3 \cdot 19 \\
3 \cdot 32 \\
2 \cdot 01\end{array}$ & $\begin{array}{r}2439 \\
7303 \\
2835 \\
1265 \\
273 \\
2574 \\
356\end{array}$ & $\begin{array}{l}0.22 \\
1.72 \\
1.23 \\
1.65 \\
3.19 \\
2.44 \\
1.30\end{array}$ & $\begin{array}{l}4 \cdot 14 \\
5 \cdot 93 \\
4 \cdot 14 \\
7 \cdot 24 \\
5 \cdot 99 \\
7 \cdot 17 \\
4 \cdot 95\end{array}$ \\
\hline
\end{tabular}

GM = Geometric mean; GSD = geometric standard deviation; Background = exposure level in the control group. 
Table 2 Characteristics of study participants

\begin{tabular}{|c|c|c|}
\hline Characteristics & $\begin{array}{l}\text { Exposed } \\
(n=79)\end{array}$ & $\begin{array}{l}\text { Unexposed } \\
(n=27)\end{array}$ \\
\hline $\begin{array}{l}\text { Mean age }(y(\mathrm{SD})) \\
\text { Mean height }(\mathrm{cm}(\mathrm{SD})) \\
\text { Sex (men) }(\%) \\
\text { Race (white) }(\%) \\
\text { Smokers }(\%) \\
\text { Mean pack-years smoking (SD) } \\
\text { Mean duration of employment }(\mathrm{y}(\mathrm{SD}))\end{array}$ & $\begin{array}{c}34 \cdot 0(7 \cdot 8) \\
176 \cdot 5(6 \cdot 7) \\
78(98 \cdot 7) \\
75(94 \cdot 9) \\
29(36 \cdot 7) \\
9 \cdot 2(13 \cdot 8) \\
8 \cdot 7(6 \cdot 3)\end{array}$ & $\begin{array}{l}40.9(11 \cdot 1) \\
178 \cdot 6(7 \cdot 9) \\
25(92 \cdot 6) \\
26(96 \cdot 3) \\
14(50 \cdot 0) \\
14.0(20 \cdot 4) \\
11.9(7 \cdot 5)\end{array}$ \\
\hline
\end{tabular}

measurements, from setting up the Miniram and the in line gravimetric filter to downloading the datalogger for each subject sample and proper handling of the filter in preparation for weighing.

\section{Results}

Table 1 presents the distribution of exposure by dust types. In general, the TWA-0.25 had lower geometric mean values and larger geometric standard deviation, suggesting that most 15 minute intervals were associated with low exposures and characterised by greater variation. It also shows that the two exposure indices were positively correlated.

Table 2 summarises the demographic characteristics of the participants by exposure state. On average, the unexposed subjects were about seven years older than those in the exposed group. The group also had a higher percentage of current smokers $(50 \% v 37 \%)$ and more pack-years of smoking (14.0 $v 9.2)$. As there were only three women and five non-white subjects, sex and race could not be evaluated in the subsequent analysis.

Table 3 presents the incidence rates of symptoms by exposure category and rate ratios by current smoking. In all symptom categories, the exposed subjects experienced higher incidence rates than the unexposed group, with the exception of eye irritation among smokers. Altogether, nasal irritation was the most frequently reported symptom, followed by cough, irritation of throat and eyes, and breathless- ness. There was no nose bleeding reported and sneezing events were too few ( 13 episodes) to warrant a separate dose-response analysis.

It is of interest that non-smokers had greater rate ratios than current smokers in all symptom categories except breathlessness. This was true although the absolute magnitude of the incidence rates for throat irritation, cough and breathlessness were higher among smokers than the non-smokers in both exposed and unexposed groups.

Figure 1 shows the incidence rates of each symptom categorised by the TWA- 6 exposure. Figure 2 presents incidence rates, stratified by TWA-0.25 exposure. For ease of comparison the denominators for both of these figures are in units of 15 minutes. An increased incidence rate with raised exposure for each symptom was evident, indicating the existence of a dose-response relation in both figures. The linear trend tests were significant at $p<0.05$ for all symptom groups. For eye irritation and breathlessness, dose-response slopes appeared to be comparable using the two different exposure indices. For nasal and throat irritation and cough, considerably steeper slopes were seen when short term exposure estimates were used.

The two exposure intervals, daily TWA and short term TWA, were further compared by using each in turn and fitting logistic regression models for "any symptom" (table 4). For this analysis and the one in table 5, a subject can contribute multiple observations, which may fall into different exposure categories. Each exposure unit was factored into a series of dummy variables for increasing exposure categories. Although monotonically increasing odds ratios were found (from 1.0 to 8.7) for increasing daily TWA- 6 exposure (model 1), a steeper doseresponse trend was seen for the TWA- $0 \cdot 25$ categories (from 1.0 to $15 \cdot 1$ ) (model 2).

To examine the effect of daily and short term exposure while accounting for the other, both exposure types were included in the same logistic regression model (model 3) (table 5). When this was

Table 3 Acute symptom rate ratios by current smoking state

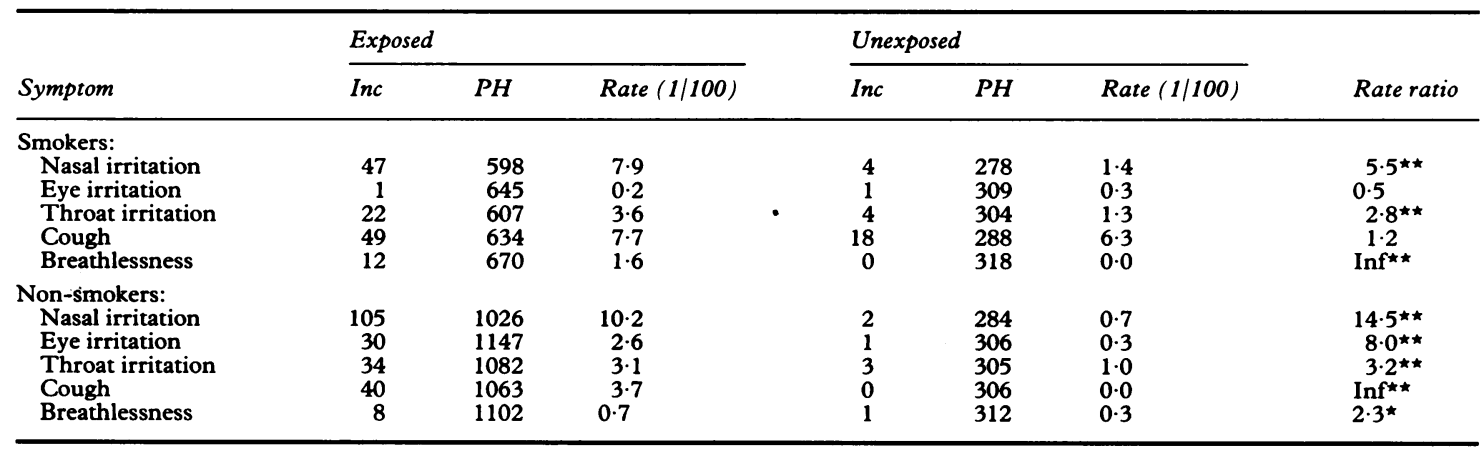

${ }^{\star} \mathrm{p}<0.05 ;{ }^{\star \star} \mathrm{p}<0.01 ;$ Inc = Incidence; PH = person-hours at risk; Inf = infinity. 


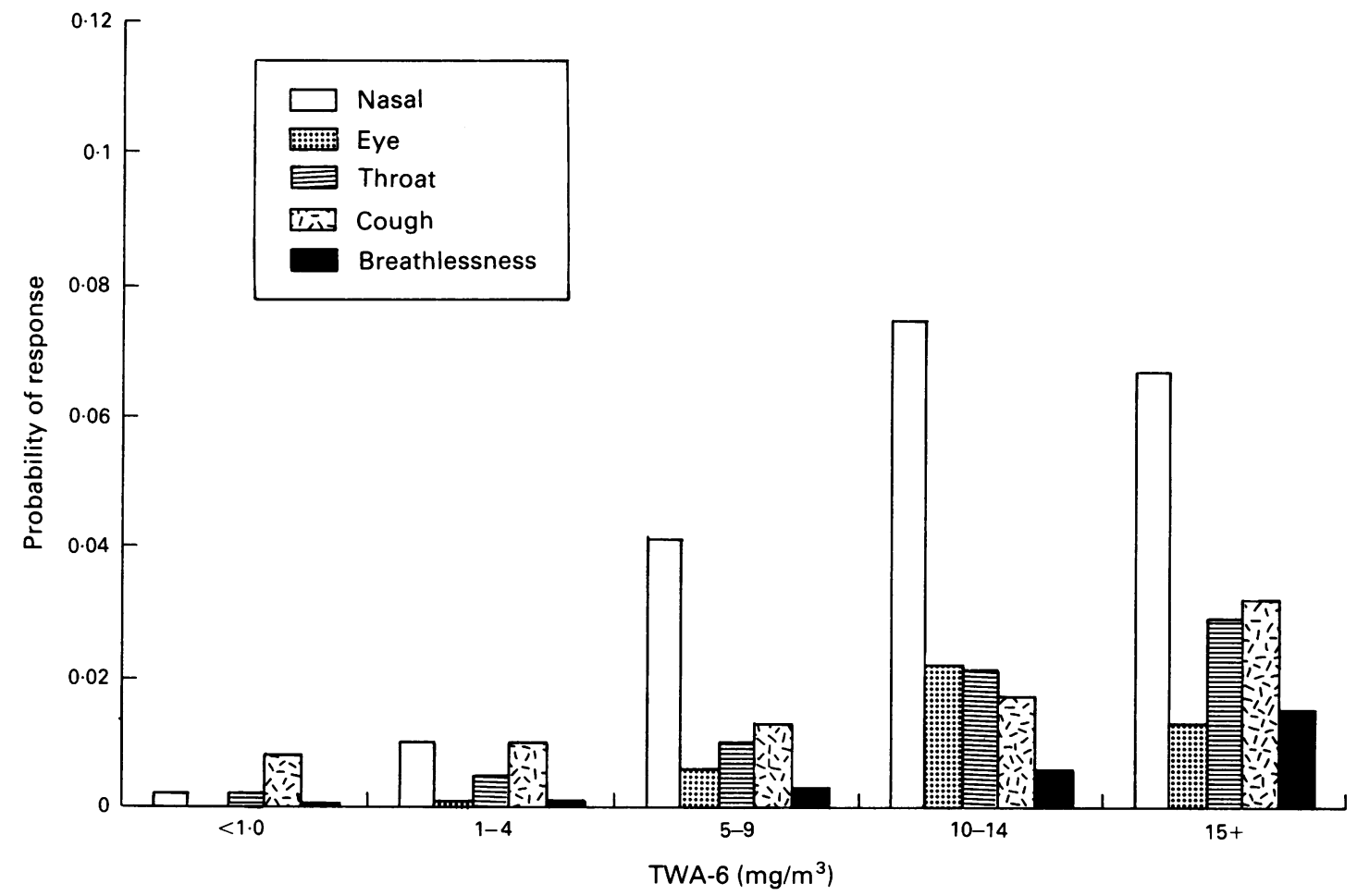

Figure 1 Probability of response in any 15 minute interval on days with specified TWA-6.

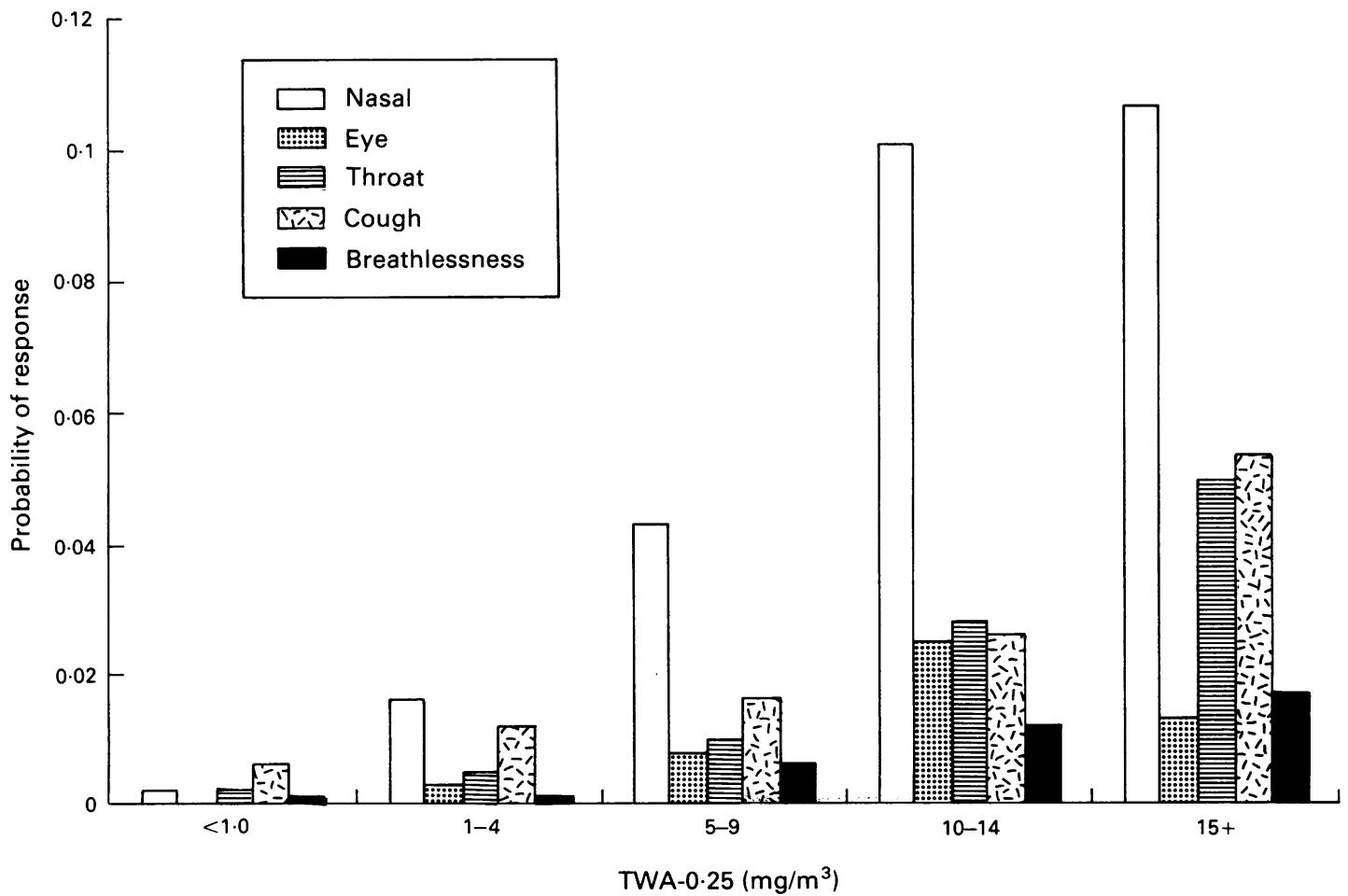

Figure 2 Probability of response categorised by exposure in each 15 minute interval. 
Table 4 Odds ratios (ORs) from logistic regression analysis for any symptom using different exposure indices

\begin{tabular}{|c|c|c|c|c|}
\hline $\begin{array}{l}\text { Exposure } \\
\left(\mathrm{mg} / \mathrm{m}^{3}\right)\end{array}$ & Coefficient & $S E$ & $O R$ & $(95 \% C I)$ \\
\hline \multicolumn{5}{|c|}{ Model 1 (TWA-6) } \\
\hline $\begin{array}{c}<1 \\
1-4 \\
5-9 \\
10-14 \\
\geqslant 15\end{array}$ & $\begin{array}{l}\overline{0.55} \\
1.65 \\
2.12 \\
2.17\end{array}$ & $\begin{array}{l}- \\
0.20 \\
0.20 \\
0.23 \\
0.20\end{array}$ & $\begin{array}{l}1 \cdot 0 \\
1.7 \\
5 \cdot 2 \\
8 \cdot 3 \\
8 \cdot 7\end{array}$ & $\begin{array}{l}-(1 \cdot 2-2 \cdot 6) \\
(3 \cdot 5-7 \cdot 7) \\
(5 \cdot 3-13 \cdot 1) \\
(5 \cdot 9-12 \cdot 9)\end{array}$ \\
\hline \multicolumn{5}{|c|}{ Model 2 (TWA-0.25) } \\
\hline $\begin{aligned}<1 \\
1-4 \\
5-9 \\
10-14 \\
\geqslant 15\end{aligned}$ & $\begin{array}{l}- \\
0.95 \\
1.72 \\
2.45 \\
2.71\end{array}$ & $\begin{array}{l}- \\
0 \cdot 18 \\
0.22 \\
0.25 \\
0.20\end{array}$ & $\begin{array}{r}1 \cdot 0 \\
2 \cdot 6 \\
5 \cdot 6 \\
11 \cdot 6 \\
15 \cdot 1\end{array}$ & $\begin{array}{c}- \\
(1 \cdot 8-3 \cdot 7) \\
(3 \cdot 6-8 \cdot 6) \\
(7 \cdot 1-18 \cdot 9) \\
(10 \cdot 2-22 \cdot 2)\end{array}$ \\
\hline
\end{tabular}

done, a strong linear dose-response trend remained for the TWA- $0 \cdot 25$ exposure profile, whereas much of the effect from the TWA- 6 disappeared. It should be pointed out, however, that the purpose of these analyses is to compare the relevance of one exposure index over the other, not to quantify the net effect of risk associated with a particular exposure index.

Table 6 considers the confounding by the logistic regression analyses. Odds ratios are displayed along with their $95 \%$ confidence intervals for each symptom and "any symptom" based on a continuous measure of TWA-6 dust exposure levels. Note that the number of observations differed between the symptom models because only the person time at risk, which varied by symptom, was included in each model. Only exposed subjects were included in this analysis as characterisation of dust type was not possible for unexposed subjects. Dust concentration was significantly associated with symptom responses after adjusting for the effects of age, current cold, smoking, and type of dust. A current cold was shown as a significant risk factor for throat irritation, cough, and breathlessness. Current cigarette smoking was negatively related to each symptom although the confidence intervals included one except "any symptom". Age over 40 was also negatively related to the reported symptoms. The model did not indicate that anhydrous borate was more potent than the other dust types after controlling for exposure and other risk factors. The interactions of exposure with these covariates were also examined, but no significant interactions were found.

To consider correlated outcomes within workers, a two stage logistic regression analysis was performed for 25 subjects who had a minimum of three symptom reports. Table 7 presents the weighted average of the three stage I parameters estimated in each of 25 separate models. This analysis suggested that there was within subject correlation of measured symptoms, as the two state Markov chain covariate was significant. The dust exposure level (TWA-0.25) was also significantly associated with the reporting of "any symptom". No day to day carryover effect was indicated.

The possible acute effects of smoking a cigarette on the irritant response was examined in the subset of frequent responders who were also current smokers. Separate logistic regression models were fitted to the data of the seven current smokers who had a minimum of three episodes of combined symptoms over surveys. Cigarette smoking in each survey hour was significantly associated with lower risk upon adjustment of short term exposure level, the Markov chain covariate, and the effect of workday.

\section{Discussion}

The irritant symptoms described in this report may reflect the responses of different target organs, but they have some common characteristics that are not present for other health related problems. They are all subjective, predominantly reversible, and likely to result from short term peak exposures.

To accommodate these features, a new approach was developed. ${ }^{8}$ A short closed ended questionnaire taking no more than two minutes to administer was conducted hourly throughout consecutive workdays. This allowed workers to report multiple episodes of acute irritation, with more accurate recall of irritant events and their onset time. A continuous real time personal air sampler permitted the examination of dose-response relations by different temporal patterns of exposure-namely, 15 minute, hourly, and daily average exposure. The findings from this study show the usefulness of this approach.

The acute irritant symptoms targeted for investigation were based on the results from earlier cross sectional studies. ${ }^{910}$ These studies did not have precise information on exposure, or precision on the specific timing of the symptoms. Because they were cross sectional, symptoms included the composite of prevalent and incident events. In the most detailed of

Table 5 Odds ratios from logistic regression analysis for any symptom with both exposure indices in the model

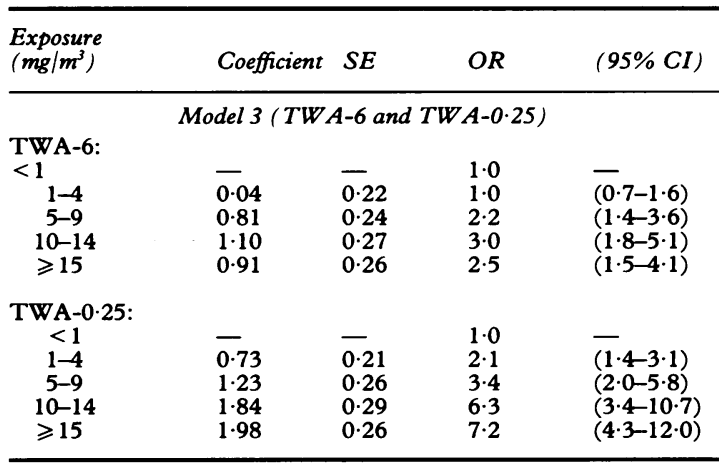


Table 6 Odds ratios from logistic models for acute symptoms based on TWA-6 dust exposure in exposed subjects

\begin{tabular}{|c|c|c|c|c|c|c|}
\hline Variable & $\begin{array}{l}\text { Nasal irr } \\
(n=252)\end{array}$ & $\begin{array}{l}\text { Eye irr } \\
(n=274)\end{array}$ & $\begin{array}{l}\text { Throat irr } \\
(n=279)\end{array}$ & $\begin{array}{l}\text { Cough } \\
(n=260)\end{array}$ & $\begin{array}{l}\text { Breathlessness } \\
(n=272)\end{array}$ & $\begin{array}{l}\text { Any symptom } \\
(n=282)\end{array}$ \\
\hline $\begin{array}{l}\text { Dust } \\
\text { Age } \\
\text { Cold } \\
\text { Smoking } \\
\text { Anhydrous }\end{array}$ & $\begin{array}{l}1.13(1.08-1.19) \\
0.13(0.04-0.46) \\
1.57(0.65-3.74) \\
0.51(0.23-1.10) \\
1.42(0.70-2.87)\end{array}$ & $\begin{array}{l}1.09(1.03-1 \cdot 16) \\
0.09(0.01-1.88) \\
1.36(0.33-5.54) \\
0.15(0.02-1.30) \\
0.47(0.09-2.36)\end{array}$ & $\begin{array}{l}1.08(1.03-1 \cdot 13) \\
0.07(0.01-0.76) \\
3.33(1.33-8.29) \\
0.90(0.35-2.29) \\
0.88(0.33-2.36)\end{array}$ & $\begin{array}{l}1.06(1.01-1.11) \\
0.20(0.04-0.99) \\
8.47(3.07-23.6) \\
0.79(0.30-2.04) \\
0.64(0.22-1.81)\end{array}$ & $\begin{array}{l}1.09(1.03-1 \cdot 15) \\
0.21(0.02-2 \cdot 82) \\
6.95(1.91-25.4) \\
0.94(0.23-3 \cdot 70) \\
0.66(0.11-3.69)\end{array}$ & $\begin{array}{l}1.13(1.08-1.19) \\
0.17(0.06-0.48) \\
1.46(0.68-3.22) \\
0.45(0.22-0.87) \\
1.03(0.55-1.90)\end{array}$ \\
\hline
\end{tabular}

$95 \%$ CIs for parameter estimate in parentheses.

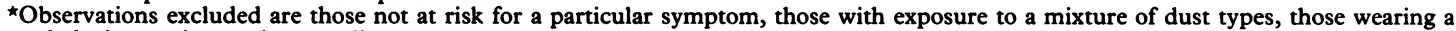
mask during testing, and one outlier.

†Variables in the models are defined as: dust $\left(\mathrm{mg} / \mathrm{m}^{3}\right)$; age $(<40, \geqslant 40)$; current cold (Yes, No); current smoking (Yes, No); anhydrous $(1$ if anhydrous, 0 if otherwise).

these studies, Garabrant et al defined four ranked exposure categories, with means that varied from $1 \cdot 1$ to $14.6 \mathrm{mg} / \mathrm{m}^{3}{ }^{4}$. The risk ratios for nose and throat irritation, eye irritation, cough, and breathlessness for the highest $v$ lowest exposure groups were roughly $15 \cdot 0,9 \cdot 3,9 \cdot 0$, and 5.0 respectively.

Direct comparisons between the study of Garabrant et $\mathrm{l}^{4}$ and the one reported here are difficult given the different categorisations of exposure. The data presented here indicate that risk ratios for the $10-14 \mathrm{mg} / \mathrm{m}^{3}$ group $v<1 \mathrm{mg} / \mathrm{m}^{3}$ group were $30 \cdot 0$, $83.6,8 \cdot 0,2 \cdot 3$, and $2 \cdot 0$, for nasal, eye, and throat irritation, cough and breathlessness respectively. Standardising for the difference in exposure between the high and lower groups, this comparison suggests that the results of the exposure-response analysis based on daily average exposures are generally consistent with those reported by Garabrant et al. ${ }^{4}$

As with other epidemiological studies in which subjective recall of health events is elicited, biased reporting can either mask an existing dose-response relation or produce a spurious association. It is possible that the subjects overstated their symptoms simply because they were intensively monitored; however, general over-reporting of symptoms would not have produced an exposure-response relation.

It is also possible that the exposed participants were aware of their exposures and attempted to report symptoms to concur with visible dust clouds. This would be expected to lead to a good deal of error in the coordination of responses to 15 minute periods and this sort of systematic reporting bias should

Table 7 Weighted average odds ratios from two stage logistic regression analysis for subjects with three or more episodes of symptoms during survey days $(n=25)$

\begin{tabular}{lll}
\hline Variable & $O R$ & $(95 \% C I)$ \\
\hline Dust & 1.03 & $(1.01-1 \cdot 04)$ \\
Work day & 0.76 & $(0.38-1 \cdot 50)$ \\
Markov (previous symptom) & 2.00 & $(1 \cdot 14-3.51)$ \\
\hline
\end{tabular}

*Variables in model are included as follows: dust $\left(\mathrm{mg} / \mathrm{m}^{3}\right)$; workday (0 of the first work day, 1 otherwise); Markov (previous symptom) $(0,1)$. result in a steeper exposure-response for TWA-6 than for TWA-0.25. In our study, however, the reverse was found.

Evidence for the validity of symptom reporting was provided by the findings for the common cold in the logistic regression analysis. Current cold was not found to be associated with nasal and eye irritation. It was, however, a strong risk factor for throat irritation, cough and breathlessness, symptoms generally associated with common colds.

In the evaluation of short term peak exposures related to symptom responses, some misclassification would inevitably occur when subjects were asked to assign the onset of a reported symptom to the closest 15 minute interval. The measurement error, due to faulty memory in this case, is non-differential and would result in a bias towards the null. With the hourly measurements of symptoms, the recall error was kept to the minimum, and its presence would only mean that the observed risk of the exposure may have been underestimated. Possible misclassification in TWA-6 occurred to the extent that exposure averaged over the entire workday was paired with symptoms that occurred at any point throughout the day, including early in the morning. Again such misclassification would have been non-differential.

Another potential bias that may exist in this study is the selection bias - that is, a healthy worker effectdue to most subjects having had substantial employment experience. Consequently, the results may not be directly generalisable to short term employees.

Results suggest that both daily exposures and short term peak exposures were linearly related to symptom responses. As expected, however, daily TWA exposures were positively correlated with short term peak exposures. Thus the dose-response trends found using daily exposure may, in fact, reflect the effect of short term peak exposures or vice versa. Results from fitting logistic regression models including both exposure profiles indicate that short term peak exposures were primarily responsible for the excess of the symptom reports.

The significant correlation between repeated out- 
comes of the same worker can be interpreted either as a "tendency to report" factor which differed from person to person, or as a result of previous symptoms causing the subjects to be more susceptible to subsequent exposure to dust. The existence of correlated symptoms, however, would not have weakend our interpretation of routine logistic regression analysis, because multiple symptom reporting for a given day was not considered in the model. Also, stage I of the two stage models did not suggest any carry over effect of symptom responses from day to day.

Current smokers appeared to be less sensitive to the irritant effects of borax dusts. In the stratified analysis, we found that the exposed smokers had lower incidence rate ratios in all symptom categories than the exposed non-smokers. The effect of smoking, however, seemed to be differential. For specific symptoms in the exposed workers, the smokers had lower incidence rates for nasal and eye irritation, but higher incidence rates for cough, breathlessness and throat irritation compared with the exposed non-smokers. This pattern was less apparent in the unexposed group except for cough. Overall, however, there was a lower incidence of symptoms in this group. Clearly, smoking itself is a form of irritation. Likewise, constant exposure to smoke might reduce the sensitivity of the nervous system to irritation of mucous membranes other than the area directly exposed to smoke. Although smokers may have been exposed to lower dust exposure, this was not supported by the multivariate logistic regression analysis. Odds ratios of less than 1 were associated with smoking in all symptom categories, after controlling for the exposure and other potential risk factors.

We have shown the existence of a linear doseresponse relation between acute irritant symptoms and exposure to borax dusts with different exposure profiles. We have also shown that the short term peak exposures, rather than daily exposure levels, are likely responsible for the excess of irritant symptoms. To date, however, many occupational irritants have had no short term exposure level (STEL) promulgated. This is largely because toxicological data are not sufficient to warrant an occupational STEL for most substances. ${ }^{11}$ Even today, it is difficult to continually monitor short term exposure peaks for some airborne dusts. It is hoped that the results from this study will encourage other investigators to study the aetiological role of short term exposure levels.

We thank Peter Shen, Martin Finkel, Donald Alcorn, Dwight Culver, and Bruce Gibson for help in performing the field study and the US Borax and Chemical Corporation and the members of the International Longshoreman Union, who generously agreed to participate in this study. Dr Eisen's work was supported in part by NIEHS grant ES00154-04.

Requests for reprints to: $\mathrm{Xiaohan} \mathrm{Hu}, \mathrm{MD}, \mathrm{PhD}$, Department of Preventive Medicine, and Biostatistics, Faculty of Medicine, University of Toronto, Toronto, Ontario, Canada M5S 1 A8.

1 US Department of Health and Human Services, Public Health Service, Center for Disease Control, National Institute for Occupational Safety and Health, Hazard Section, Surveillance Branch. National occupational hazard survey. Estimate of occupational exposure to sodium borate. Cincinnati: National Institute for Occupational Safety and Health, 1982.

2 US Department of labour, Occupational Safety, and Health Administration. Air contaminants, final rule 29 CFR Part 1910, 19 January 1989 Vol 54, No 12 book 2.

3 International Labour Office. Encyclopedia of occupational health and safety. Geneva: ILO, 1983.

4 Garabrant DH, Bernstein L, Peters JM, Smith TJ, Wright WE. Respiratory effects of borax dust. Br J Ind Med 1985;42:831-7.

5 Eisen EA, Wegman DH, Kriebel D, Woskie SW, Hu X. An epidemiologic approach to the study of acute reversible health effects in the workplace. Epidemiology 1991;2:263-70.

6 American Conference of Governmental Industrial Hygienists. 1990-1991 Threshold limit values for chemical substances and physical agents and biologic exposure indices. Cincinnati, 1990.

7 Korn EL, Whittemore AS. Methods for analyzing panel studies of acute health effects of air pollution. Biometrics 1979;35: 795-802.

8 Wegman DW, Eisen EA, Design for epidemiologic studies of acute effects of respiratory irritation. In: Hogstedt C, Reuterwall C, eds. Progress in occupational epidemiology. Excerpta Medica International Congress Series 829, 1988.

9 Birmingham DJ, Key MM. Preliminary survey. US borax plant, Boron, California (February 20, 1963). Cincinnati: Occupational Health Research and Training Facility, Division of Occupational Health, Public Health Service, US Department of Health and Welfare, 1963.

10 Hogan WD. Boron study, preliminary report. Berkeley, Ca: Bureau of Occupational Health, California State Department of Public Health, 1965.

11 Ulfvarson U, Tech $D$. Assessment of concentration peaks in setting exposure limits for air contaminants at workplaces, with special emphasis on narcotic and irritative gases and vapors. Scand J Work Environ Health 1987;13:389-98.

Accepted 2 December 1991 